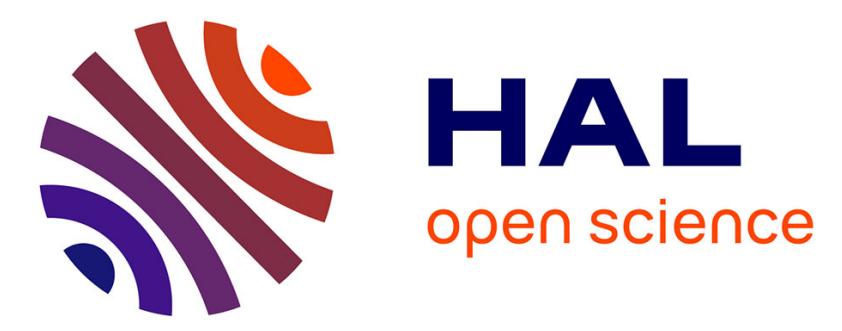

\title{
Dental morphology and wear pattern in Tachyoryctes (Spalacidae, Rodentia)
}

\author{
Raquel López-Antoñanzas
}

\section{To cite this version:}

Raquel López-Antoñanzas. Dental morphology and wear pattern in Tachyoryctes (Spalacidae, Rodentia). Mammalia, 2012, 76 (3), pp.309-314. 10.1515/mammalia-2012-0018 . hal-01920838

\section{HAL Id: hal-01920838 \\ https://hal.science/hal-01920838}

Submitted on 12 Dec 2020

HAL is a multi-disciplinary open access archive for the deposit and dissemination of scientific research documents, whether they are published or not. The documents may come from teaching and research institutions in France or abroad, or from public or private research centers.
L'archive ouverte pluridisciplinaire HAL, est destinée au dépôt et à la diffusion de documents scientifiques de niveau recherche, publiés ou non, émanant des établissements d'enseignement et de recherche français ou étrangers, des laboratoires publics ou privés. 


\section{Dental morphology and wear pattern in Tachyoryctes (Spalacidae, Rodentia)}

\author{
Raquel López-Antoñanzas \\ Departamento de Paleobiología, Museo nacional de \\ Ciencias naturales-CSIC, C/ José Gutiérrez Abascal 2, \\ 28006 Madrid, Spain, e-mail: ralopan@mncn.csic.es
}

\begin{abstract}
Tachyoryctes, the most derived genus within the tribe Tachyoryctini (Rhizomyinae, Spalacidae, Rodentia), is known from Pliocene to Recent. It comprises four species: the fossil T. pliocaenicus and T. konjiti and the extant T. splendens and T. macrocephalus. A detailed description of the morphology and dental wear pattern of the cheek teeth of T. splendens is provided based on the study of 297 skulls. For the first and second lower and upper molars, five stages of wear are recognized $(0-4)$. The third lower and upper molars show four stages of wear (0-3). The dental wear pattern in T. splendens is comparable to that of the Pleistocene T. konjiti.
\end{abstract}

Keywords: dental wear pattern; Mammalia; Rhizomyinae; systematics; Tachyoryctini.

\section{Introduction}

The Tachyoryctini are a tribe of spalacid rodents within the subfamily Rhizomyinae (Flynn 2009, López-Antoñanzas and Wesselman in press, López-Antoñanzas et al. in preparation). The most derived members belong to the genus Tachyoryctes (Rüppell, 1836), which is known since Pliocene times (LópezAntoñanzas et al. in preparation). Three fossil species of this genus have been recognized: T. makooka Wesselman (Black and Asnake 2009), T. pliocaenicus (Sabatier 1978) and T. konjiti (Sabatier 1982). However, recent detailed studies have revealed that T. makooka belongs in fact to a more primitive genus: Protachyoryctes (Hinton 1933) (López-Antoñanzas and Wesselman in press, López-Antoñanzas et al. in preparation). The number of extant species of Tachyoryctes considered valid has varied through time. According to Hollister (1919: pp. 40), Tachyoryctes comprised eight species. Later, Allen (1939: pp. 361-363) and Ellerman (1941) included 14 species in this genus. In 1971, Misonne provided a census of the valid extant species of Tachyoryctes in which he concluded that only two species exist at present: T. splendens (Rüpell 1836), and T. macrocephalus (Rüppell 1842). This was followed by subsequent authors (Rahm 1980: pp. 23-27, Bucher 1982: p. 478, Yalden 1985, Corbet and Hill 1991). Musser and Carleton $(1993,2005)$ pointed out that there was no justification for reducing the number of species (from 14 to 2 ) belonging to
Tachyoryctes so abruptly and, therefore, they cautiously recognized 11 (Musser and Carleton 1993: pp. 685-687) and 13 (Musser and Carleton 2005: pp. 922-926) taxa. However, on the basis of morphometric analyses carried out on 522 skulls, Beolchini and Corti (2004) could only distinguish two species of Tachyoryctes. I consider reasonable the validity of only the two species previously recognized by Misonne (1971). African Tachyoryctini are nowadays discontinuously distributed in the centre and, especially, the eastern part of the continent (Democratic Republic of the Congo, Uganda, Rwanda, Burundi, Tanzania, Kenya, Ethiopia, Somalia and possibly South Sudan and Eritrea). Tachyoryctes splendens is known in a wide variety of habitats (tropical humid forest and open woodland, savannah, grasslands and agricultural areas) and is widely distributed in East Africa and eastern areas of Central Africa. In contrast, T. macrocephalus is restricted to the alpine grassland of the Bale Mountains of Ethiopia (IUCN 2010).

The dental morphology of fossil Tachyoryctes, as well as that of more primitive Tachyoryctini, has been described in detail (Sabatier 1978, 1979, 1982, Flynn 1982, Wesselman et al. 2009, López-Antoñanzas and Wesselman in press). Surprisingly, this morphology has not been adequately described in modern representatives of Tachyoryctes. The aim of the present paper is to provide an in-depth description of the dental morphology and dental wear pattern in T. splendens.

\section{Materials and methods}

The study presented below is based on the examination of original specimens, casts and data from the literature. The specimens mentioned are housed in the following institutions: Catalogue général du Laboratoire des Mammifères et Oiseaux, Muséum national d'Histoire naturelle, Paris, France (C.G.); Mammalogie-Sammlung, Forschungsinstitut und Naturmuseum Senckenberg, Frankfurt am Main, Germany (SMF); Zoologische Sammlung, Museum für Naturkunde der Humboldt-Universität, Berlin, Germany (ZMB). I examined: skulls of extant Tachyoryctes macrocephalus ZMB 36656, ZMB 55165, ZMB 36649 and C.G. 1972-73, C.G. 1972-74, C.G. 1972-75, C.G. 1972-76, C.G. 1974-202 and T. splendens (ZMB 12, ZMB 78, ZMB 79, ZMB 80, ZMB 81, ZMB 83, ZMB 88, ZMB 114, ZMB 117, ZMB 3404, ZMB 3403, ZMB 9015, ZMB 16048, ZMB 28069, ZMB 36601-13, ZMB 36618, ZMB 36620-36621, ZMB 36624-36634, ZMB 36636-36637, ZMB 36640-36646, ZMB 36648, ZMB 36650-36655, ZMB 46257, ZMB 48300, ZMB 72559-72593, ZMB 7721 and C.G. 1993-217, C.G. 1993-231, C.G. 1993220, C.G. 1993-238, C.G. 1933-2752, C.G. 2000-685, C.G. 1961-33, C.G. 1972-10, C.G. 1972-27, C.G. 1972-39, C.G. 
1972-51, C.G. 1972-64, C.G. 1972-65, C.G. 1972-68, C.G. 1993-222, C.G. 1993-225, C.G. 1993-241, C.G. 1993-246, C.G. 1993-250, C.G. 1993-253, C.G. 1993-254, C.G. 1993-257, C.G. 1993-263, C.G. 1993-265, C.G. 1993-268, C.G. 1993-272, C.G. 1993-274, C.G. 1993-289, C.G. 1993302, C.G. 1993-303, C.G. 1993-308, C.G. 1993-323, C.G. 1933-2746, C.G. 1933-2756, C.G. 1905-385, C.G. 19332745, C.G. 1933-2748, C.G. 1960-454, C.G. 1962-2292, C.G. 1970-210, C.G. 1972-16, C.G. 1972-19, C.G. 1972-44, C.G. 1972-46, C.G. 1972-50, C.G. 1972-54, C.G. 1972-58, C.G. 1993-221, C.G. 1993-223, C.G. 1993-232, C.G. 1993-238, C.G. 1993-245, C.G. 1993-281, C.G. 1993-288, C.G. 1993294, C.G. 1993-304, C.G. 1993-307, C.G. 1993-318, C.G. 1993-322, C.G. 1960-453, C.G. 1962-2290, C.G. 1972-14, C.G. 1972-25, C.G. 1972-29, C.G. 1972-41, C.G. 1972-57, C.G. 1974-202, C.G. 1991-629, C.G. 1993-217, C.G. 1993224, C.G. 1993-239, C.G. 1993-240, C.G. 1993-249, C.G. 1993-261, C.G. 1993-270, C.G. 1993-292b, C.G. 1993295, C.G. 1993-296, C.G. 1993-316, C.G. 1961-921, C.G. 1972-11, C.G. 1972-15, C.G. 1972-17, C.G. 1972-24, C.G. 1972-33, C.G. 1972-37, C.G. 1972-45, C.G. 1972-52, C.G. 1972-53, C.G. 1972-69, C.G. 1981-533, C.G. 1988-119, C.G. 1993-226, C.G. 1993-227, C.G. 1993-228, C.G. 1993-230, C.G. 1993-235, C.G. 1993-237, C.G. 1993-242, C.G. 1993247, C.G. 1993-259, C.G. 1993-260, C.G. 1993-267, C.G. 1993-283, C.G. 1993-284, C.G. 1993-286, C.G. 1993-287, C.G. 1993-309, C.G. 1993-310, C.G. 1993-315, C.G. 1993317, C.G. 1993-320, C.G. 1933-2747, C.G. 1972-06, C.G. 1972-21, C.G. 1972-26, C.G. 1972-30, C.G. 1972-34, C.G. 1972-43, C.G. 1972-59, C.G. 1972-62, C.G. 1972-66, C.G. 1972-67, C.G. 1993-231, C.G. 1993-234, C.G. 1993-236, C.G. 1993-256, C.G. 1993-275, C.G. 1993-278, C.G. 1993285, C.G. 1993-290, C.G. 1993-291, C.G. 1993-300, C.G. 1993-305, C.G. 1993-314, C.G. 1962-2291, C.G. 1972-09, C.G. 1972-12, C.G. 1972-31, C.G. 1972-35, C.G. 1972-40, C.G. 1972-47, C.G. 1972-61, C.G. 1988-242, C.G. 1993219, C.G. 1993-220, C.G. 1993-248, C.G. 1993-251, C.G. 1993-258, C.G. 1993-262, C.G. 1993-273, C.G. 1993-276, C.G. 1993-282, C.G. 1993-299, C.G. 1993-313, C.G. 1993321, C.G. 1933-2749, C.G. 1972-18, C.G. 1972-20, C.G. 1972-23, C.G. 1972-42, C.G. 1972-48, C.G. 1972-55, C.G. 1972-56, C.G. 1972-71, C.G. 1993-218, C.G. 1993-229, C.G. 1993-243, C.G. 1993-264, C.G. 1993-269, C.G. 1993-271, C.G. 1993-277, C.G. 1993-279, C.G. 1993-292, C.G. 1993-
297, C.G. 1993-298, C.G. 1993-306, C.G. 1993-311, C.G. 1993-319, C.G. 1993-324, C.G. 1972-07, C.G. 1972-08, C.G. 1972-13, C.G. 1972-22, C.G. 1972-28, C.G. 1972-32, C.G. 1972-36, C.G. 1972-38, C.G. 1972-49, C.G. 1972-60, C.G. 1972-63, C.G. 1972-70, C.G. 1993-233, C.G. 1993-244, C.G. 1993-252, C.G. 1993-255, C.G. 1993-266, C.G. 1993-280, C.G. 1993-293, C.G. 1993-301, C.G. 1993-312, C.G. 19332752).

First, second and third lower molars are designated as $\mathrm{m} 1$, $\mathrm{m} 2$ and $\mathrm{m} 3$, respectively, and first, second and third upper molars as MI, M2 and M3, respectively. The terminology used in the tooth descriptions follows the rodent dental terminology of Flynn (1982), with some adjustments (Figure 1).

\section{Systematics}

Genus Tachyoryctes (Rüppell 1836)

Type species. Tachyoryctes splendens (Rüppell 1836)

Referred species. Tachyoryctes macrocephalus, Tachyoryctes konjiti, Tachyoryctes pliocaenicus.

\section{Tachyoryctes splendens}

In 1836, Rüpell named a new species of rodent that he discovered in Ethiopia. In his work, he pointed out that this rodent closely resembled Bathyergus from Cape of Good Hope in the skull, crown and size of the teeth, toes and claws. However, he also noticed some singularities in the Ethiopian animal, such as the small size of its ear pinnae and its longer and more rounded tail. As very few species of the genus Bathyergus were known at that time, he refrained from naming a new genus, although eminent London and Parisian experts thought otherwise (Rüppell 1836). He suggested in a footnote the use of the name Tachyoryctes (Rüppell 1836: p. 35), should it turn out in the future that scientists wanted to transfer this species to a new genus. Rüppell (1842) reallocated this species to the genus Rhizomys, including in it the new taxon Rhizomys macrocephalus (see below) as well. The genus Tachyoryctes was accepted in Heck (1851a: p. 464) in a section written by C. Girard (Heck 1851b: p. v.). Heuglin and Fitzinger (1866: pp. 32-33) and later authors also accepted Tachyoryctes as valid and included both T. splendens and T. macrocephalus in it. The lectotype of T. splendens is (SMF) 4317 (head and skin).

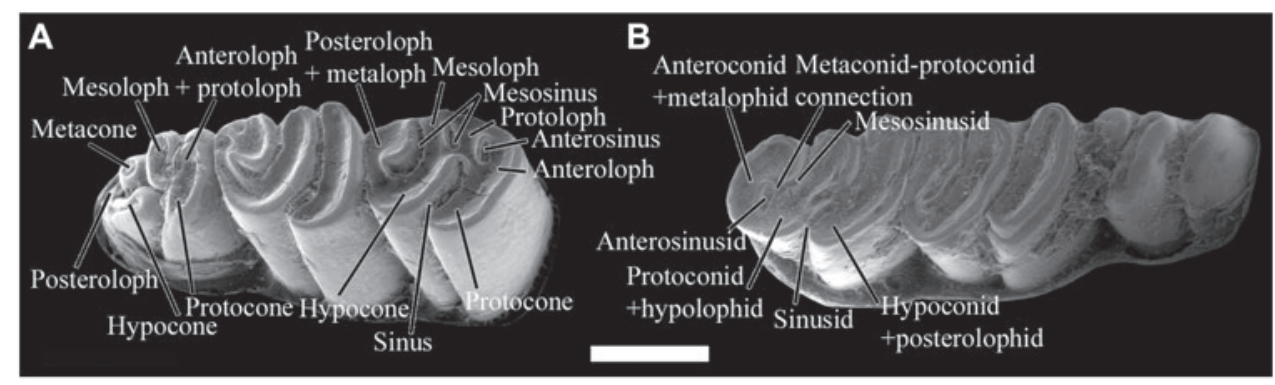

Figure 1 Tachyoryctini dental terminology used in this paper.

Tachyoryctes splendens. (A) Right upper cheek teeth. (B) Left lower cheek teeth. Scale bar equals $2 \mathrm{~mm}$. 


\section{Lower dentition}

m1 When unworn (as in specimen ZMB 28069, Figure 2A), this tooth has a cuspidate isolated anterolophid, an isolated metaconid, the entoconid connected to the protoconid and an arcuate posterolophid, which is a long continuation of the hypoconid. The mure is lacking and two long sinusids divide the tooth into three parts. This morphology is wear stage 0 .

In early wear (e.g., ZMB 12, ZMB 72686, C.G. 1933-2752, C.G. 1993-217, Figure 2C-E), the anterolophid is combined with the metaconid, forming a first lophid; the protoconid connects or nearly connects labially to the anterolophid, and it joins lingually with the metaconid. This results in the isolation of a small and oval anterolabial enamel lake (e.g., C.G. 1993-217, Figure 2C). In addition, the second lophid (combined entoconid-protoconid) joins the third one (hypoconidposterolophid) at about the midpoint of the tooth. At this stage of wear, the tooth shows an anterolabial enamel lake and three sinusids: a single labial one and two lingual ones, all of which remain open. This morphology is wear stage 1 .

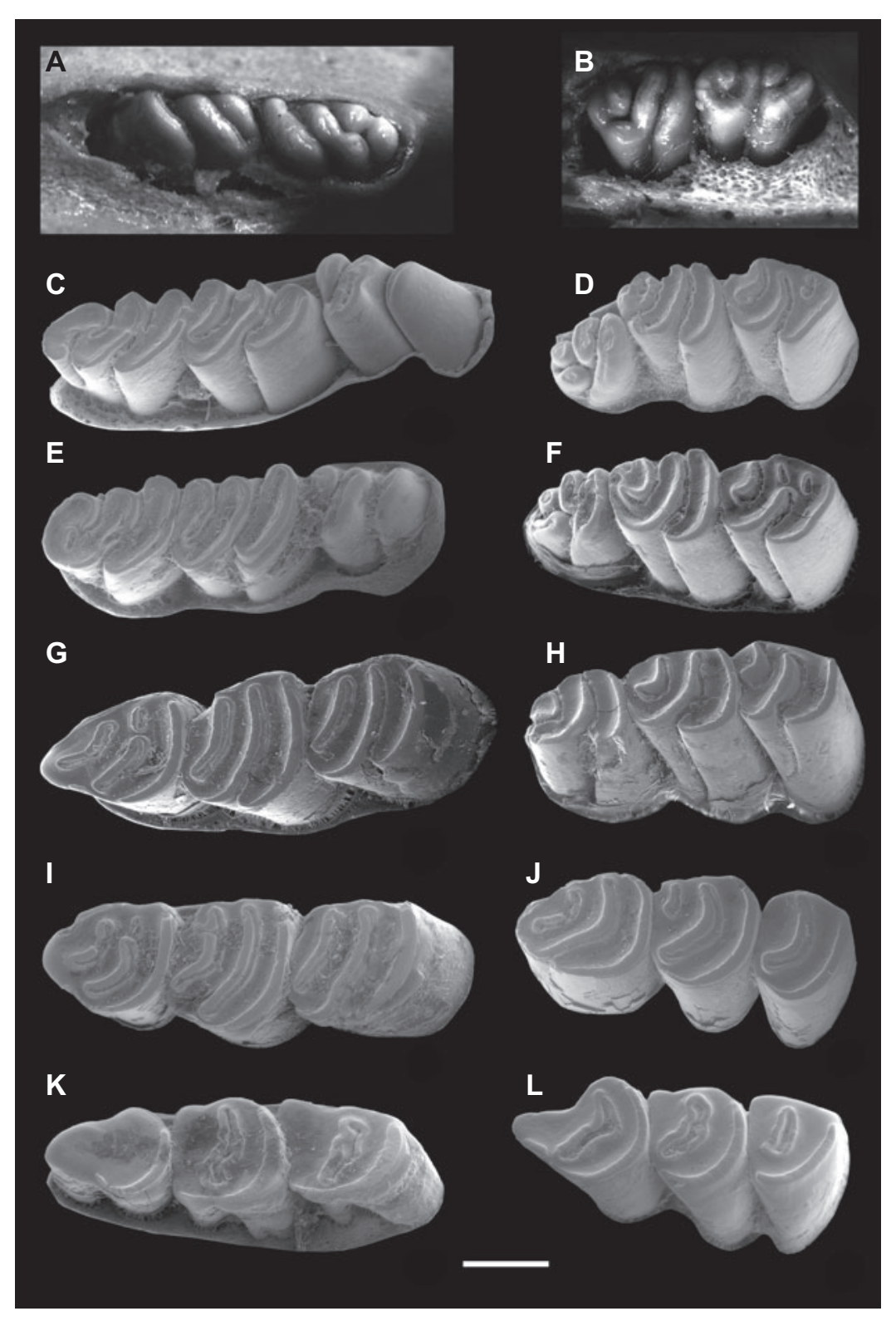

Figure 2 Dental wear pattern in Tachyoryctes splendens.

Stage of wear 0, newly born individual (ZMB 28069) (A) right hemimandible with m1-m2 in occlusal view; (B) right maxilla with M1-M2. Stage of wear 1, juvenile individual (C) left hemimandible with m1-m3 in occlusal view (C.G. 1933-2752); (D) left maxilla with M1-M3 in occlusal view (C.G. 1933-2752). (E) (C.G. 1993-217) (F) (C.G. 1993-217). Stage of wear 2 (G) left hemimandible with m1-m3 in occlusal view (C.G. 1993-231) (H) left maxilla with м1-м3 in occlusal view (C.G. 1993-231). Stage of wear 3 (I) left hemimandible with m1-m3 in occlusal view (C.G. 1993-220) (J) left maxilla with м1-M3 in occlusal view (C.G. 1993-220). Stage of wear 4 (K) left hemimandible with m1-m3 in occlusal view (C.G. 1993-238) (L) left maxilla with M1-M3 in occlusal view (C.G. 1993-238). Scale bar equals 2.5 mm. 
After moderate wear, the anterolabial enamel lake disappears (e.g., ZMB 36610) or is confluent with the anterolingual one, forming an elongated anterior enamel lake (e.g., ZMB 36643, C.G. 1993-231, Figure 2G). The lingual reentrants are closed off, isolating two lingual enamel lakes. The sinusid is usually closed (e.g., C.G. 1993-231, Figure 2G; ZMB 36610, ZMB 36643) but may still remain open (as in specimen ZMB 36654). The enamel disappears from the anterior side of the tooth. This morphology is wear stage 2 .

After further wear, the morphology of the tooth is similar to the preceding stage, but the loss of enamel may be more marked (e.g., C.G. 1993-220, Figure 2I). This morphology corresponds to wear stage 3 .

Later, the tooth is completely worn and only a flat surface (devoid of enamel lakes) shows (e.g., C.G. 1993-238, Figure $2 \mathrm{~K})$. Except for the posterior side of the tooth, the enamel has completely disappeared. This morphology corresponds to wear stage 4 .

m2 When unworn (as in specimen ZMB 28069, Figure 2B) this tooth shows three oblique lophids: the anterolophidmetaconid, the entoconid-protoconid and the hypoconidposterolophid. The first one joins the second one labially through the protoconid. The posterolophid is a simple arcuate structure isolated from the rest of the crown by a long reentrant (the sinusid). The mure is lacking. At this stage of wear, there are two open, oblique and very elongated reentrants. This morphology corresponds to wear stage 0 .

In early wear (e.g., ZMB 12, ZMB 72686, C.G. 1933-2752, C.G. 1993-217, Figure 2C-E), the tooth is more lophodont than specimens at the previous wear stage, and the connection between the two anterior lophids is much stronger. This morphology corresponds to wear stage 1 .

After moderate wear, the tooth is anteroposteriorly reduced. The three oblique lophids of wear stage 1 are still present. With regard to the reentrants, the anterosinusid is closed off, isolating an elongated anterior enamel lake. This lake parallels the sinusid, which still remains open (C.G. 1993-231, Figure 2G). This morphology corresponds to wear stage 2 .

In later wear, the sinusid closes (C.G. 1993-220, ZMB 36643, Figure 2I) and isolates an elongated central enamel lake. The anterior and posterior enamel lakes are curved toward the anterior side of the tooth. In addition, the anterior enamel lake is somewhat reduced with respect to the previous stage of wear. This morphology corresponds to wear stage 3 .

With more wear the anterior labial lake disappears, and only an elongate central enamel lake persists (e.g., C.G. 1993238 , Figure $2 \mathrm{~K}$ ). This morphology corresponds to a fourth stage of wear.

m3 When unworn (e.g., ZMB 12, ZMB 72686, C.G. 19332752, C.G. 1993-217, Figure 2C-E) the tooth shows three isolated lophids: the anterolophid-metaconid, the protoconidentoconid and the short hypoconid-posterolophid. The first and second lophids are connected labially through the protoconid. The third lophid is an arcuate structure completely isolated from the rest of the crown by a long reentrant. This morphology corresponds to wear stage 0 . When the $\mathrm{m} 3$ is at this stage of wear, the $m 1$ and $m 2$ are at their first stage of wear.

In early wear, the anterosinusid is closed off and isolates an elongated anterior enamel lake that is parallel to the sinusid. The latter remains open labially; it divides the crown into two parts (e.g., C.G. 1993-231, Figure 2G). This morphology corresponds to wear stage 1 . When the $\mathrm{m} 3$ is at this point, the $\mathrm{m} 1$ and $\mathrm{m} 2$ are at their second stage of wear.

At moderate wear, the anterior enamel lake may be reduced, and the sinusid may close off (ZMB 9015). In this case, an elongated and anteriorly curved central enamel lake is delimited. However, in some specimens, the sinusid remains open (e.g., C.G. 1993-220, Figure 2I). This morphology corresponds to wear stage 2 . When the $\mathrm{m} 3$ is at this point, the $\mathrm{m} 1$ and $\mathrm{m} 2$ are in wear stage 3 .

In later wear, the anterior labial lake disappears, and only an elongate central enamel lake persists (e.g., C.G. 1993-238, Figure $2 \mathrm{~K}$ ). This morphology corresponds to the third stage of wear. When the $\mathrm{m} 3$ is at this point, the $\mathrm{m} 1$ and $\mathrm{m} 2$ are in wear stage 4.

\section{Upper dentition}

м1 The M1 is smaller than the M2 and M3. The occlusal outline of the tooth is rectangular with the posterior side shorter than the anterior side and somewhat rounded. When unworn, the MI has a long anteroloph, a distinct and isolated protoloph, a long mesoloph that joins the hypocone, and a metacone that connects posterolabially to a short posteroloph. The mure is lacking, and the anterior part of the tooth is completely isolated from the rest of the crown by a long sinus (e.g., ZMB 28069, Figure 2B). This morphology corresponds to wear stage 0 .

In early wear (e.g., C.G. 1993-2752, C.G. 1993-217, ZMB 12, ZMB 72686, ZMB 85819, Figure 2D-F), the MI has four lophs: protocone-anteroloph, protoloph-protocone, hypoconemesoloph and hypocone-metaloph-posteroloph. All the lophs join at the labial margin of the tooth. The protoloph connects to the anteroloph and, in most specimens, to the mesoloph. In this case, the tooth has a lingual sinus and three labial enamel lakes that correspond with the former anterosinus and mesosinus. In some specimens (e.g., C.G. 1993-2752, Figure 2D), the protoloph does not connect to the mesoloph, and therefore only two enamel lakes are isolated. The most posterior enamel lake is elongate and much larger than the anterior and middle ones (when present). The sinus remains open at this stage of wear. This morphology corresponds to wear stage 1 .

After moderate wear, the protoloph and the anteroloph combine and the anterior enamel lake disappears (e.g., C.G. 1993-231, Figure 2H). The tooth shows three lophs, all of which join at their labial margin. The sinus is still open and nearly reaches the labial side of the tooth. This morphology corresponds to wear stage 2 .

In later wear, the $\mathrm{M} 1$ is significantly reduced in size. The mesoloph fuses with the posteroloph, and the sinus is closed off, isolating a single, elongate central enamel lake. At this stage of wear, the tooth shows only two lophs (e.g., ZMB 9015, ZMB 36654, ZMB 36610, ZMB 48300, C.G. 1993-220, Figure 2J). This morphology corresponds to wear stage 3 . 
With further wear, the enamel lake is reduced to a circular structure (C.G. 2010-10-11, C.G. 1993-238, Figure 2L) or completely disappears (ZMB 36641). This morphology corresponds to wear stage 4 .

M2 The occlusal outline is rectangular but somewhat rounded anteriorly and posteriorly. When unworn, the M2 shows the anteroloph, a long mesoloph that connects to the hypocone, an isolated metacone and a short posteroloph next to it. The protoloph is absent. The anterior part of the tooth is completely isolated from the posterior one by a long sinus, and the mure is lacking. All the reentrants are open. This morphology is wear stage 0 (e.g., ZMB 28069, Figure 2B).

In early wear, there are three lophs: the anteroloph, the long mesoloph and the metacone, which may fuse with the short posteroloph (e.g., ZMB 72686, ZMB 85819) or remain distinct and delimit a circular and small posterolabial sinus (C.G. 1993217, C.G. 1933-2752, Figure 2D-F). The anterior loph is completely isolated from the posterior one by a long lingual sinus, which closes off at the labial side of the tooth. The mesosinus remains open. This morphology corresponds to wear stage 1 .

After moderate wear, the M2 morphology is quite similar to the previous wear stage. However, the small labial posterosinus has completely disappeared, the mesosinus is closed off and a posterior enamel lake is formed (e.g., C.G. 1993-231, Figure $2 \mathrm{H}$ ). In addition, the labial side of the tooth has lost enamel. This morphology corresponds to wear stage 2 .

In later wear, the tooth is clearly anteroposteriorly reduced. All reentrants close off isolating two enamel lakes: the anterior, which is much smaller and located labially, and the posterior, which is very elongated and extends transversely along the occlusal surface, dividing the tooth into two parts (e.g., ZMB 48300, C.G. 1993-220, Figure 2J). In some specimens, the anterior side of the tooth connects labially to the posterior side, and the central elongate enamel lake is divided into a small and circular labial enamel lake and an elongate lingual one. In this case, the tooth has three enamel lakes (ZMB 36610). The loss of enamel extends to the entire posterior side of the tooth. This morphology corresponds to wear stage 3 .

With more wear, the anterior labial enamel lake disappears and only an elongate central lake persists (e.g., C.G. 1993-238, Figure 2L). This remnant may be divided into two small lakes: a labial circular one and a more elongate lingual one (C.G. 2010-10-11). This morphology corresponds to wear stage 4 .

M3 When unworn all the cusps of the tooth are recognizable (e.g., C.G. 1933-2752, Figure 2D). This tooth shows an anterior isolated lophid (anteroloph-protoloph), an isolated mesoloph, a short posteroloph that connects to the hypocone and an isolated metacone. This morphology corresponds to wear stage 0 . When the $\mathrm{M} 3$ is at this point, the $\mathrm{m} 1$ and $\mathrm{M} 2$ are in wear stage 1 .

In early wear (e.g., specimen C.G. 1993-231, Figure 2H), the $\mathrm{M} 3$ is much more elongated than in the previous stage of wear. The first loph connects to the middle one at the labial side of the tooth. Except for this labial contact, a very long sinus isolates the anterior side of the tooth from the posterior one. The mesoloph is transformed into a long continuation of the hypocone. It does not connect labially to the metacone. Thus, the mesosinus is open. The metacone joins with the short posteroloph. The occlusal morphology is composed of three lophs and two open sinuses. This morphology corresponds to wear stage 1 . When the $\mathrm{M} 3$ is at this point, the $\mathrm{m} 1$ and $\mathrm{M} 2$ are in wear stage 2 .

After moderate wear, the tooth is elongated with its posterior part somewhat reduced. At this stage of wear, all reentrants are usually closed off, isolating two main enamel lakes (e.g., ZBM 9015) but the sinus may still be open (e.g., C.G. 1993-220, Figure 2J). The anterior enamel lake is longer than the posterior one. Small additional enamel lakes may form if any main enamel lakes are divided (e.g., ZBM 9015). This morphology corresponds to wear stage 2 . When the $\mathrm{M} 3$ is at this point, the $\mathrm{m} 1$ and $\mathrm{M} 2$ are at wear stage 3 .

In later wear, the tooth appears very elongate with the posterior side acutely narrow. The occlusal surface is completely flat, and only an elongate posterolabially directed enamel lake is present. The enamel has disappeared from the labial and posterior borders of the tooth, but it persists on the anterior and anterolingual side. This morphology corresponds to wear stage 3 . When the $\mathrm{M} 3$ is at this point, the $\mathrm{M} 1$ and $\mathrm{M} 2$ are at wear stage 4 .

\section{Discussion and Conclusion}

Sabatier $(1978,1979,1982)$ studied in detail two Ethiopian fossil species of Tachyoryctes: the Pliocene T. pliocaenicus and the Pleistocene T. konjiti. Analyzing the teeth of this latter species, he recognized three stages of wear on M1 (wear stage 1-3), four on M2 (wear stage 1-4) and M3 (wear stage 0-3), six on $\mathrm{m} 1$ (wear stage 1-6), four on $\mathrm{m} 2$ (wear stage $0-3$ ) and three on $\mathrm{m} 3$ (wear stage 0-2).

The study of 297 skulls of the extant Tachyoryctes splendens has allowed me to determine the changes in dental wear pattern throughout life in this taxon. For the first and second lower and upper molars, five stages of wear (0-4) are recognized. The third lower and upper molars show four stages of wear (0-3). Wear stage 0 of the first and second lower and upper molars, in which the third molars are still in their crypts, is that of new-born individuals. Wear stage 1, in which the third molars have just erupted through the jaw bone, corresponds to juvenile individuals. Finally, wear stages $2-5$ are found in adult individuals.

The dental wear pattern in extant Tachyoryctes splendens is comparable to that of the extinct T. konjiti (Sabatier 1979, 1982). Both taxa show a strong difference in molar wear as the first molars are always much more worn than the more posterior ones. Some of the dissimilarities observed between the two species are due to an age bias in the sample of $T$. konjiti, in which there are neither newly born specimens nor very old adults. Therefore, wear stage 0 for the M1, M2 and $\mathrm{m} 1$, as well as the last stage of wear that is present in very old specimens of T. splendens, are lacking in T. konjiti.

After examining in detail the morphology of the cheek teeth in numerous specimens of Tachyoryctes splendens, 
I agree with most of the wear stages presented by Sabatier $(1979,1982)$ for T. konjiti. However, I would rather combine wear stages 2 and 3 for the м3 (Sabatier 1979, 1982) into wear stage 2 and combine wear stages 1-3 for the m1 (Sabatier 1979, 1982) into wear stage 1 of this study.

As shown by López-Antoñanzas et al. (in preparation), Tachyoryctes splendens is closely related to T. macrocephalus and the two extinct species T. konjiti and T. pliocenicus. It is, therefore, not surprising that $T$. splendens and $T$. konjiti show such a similar dental wear pattern. The study of dental wear patterns in extant animals and the comparison of patterns with their fossil relatives help to prevent the assignment of fossil teeth from conspecific individuals at different stages of wear to different species. By determining the relative age of these individuals, the study of dental wear patterns also allows estimation of the age-class structure of the fossil sample to which they belong.

\section{Acknowledgements}

Sincere thanks to C. Denys (Muséum National d'Histoire Naturelle, Paris) and F. Mayer and N. Lange (Museum für Naturkunde der Humboldt-Universität, Berlin) for having made available the extant rhizomyine material under their care. M. Sabatier (Canohès) answered my inquiries. J. Baskin (University-Kingsville, Kingsville) and L. Flynn (Harvard University, Cambridge) enhanced this work through careful reading. My sojourn in Berlin and Paris were funded by the SYNTHESYS Project (http://www.synthesys.info/), which is financed by European Community Research Infrastructure Action under the FP7 "Capacities" Program and by the EDIT Gender Action Plan, respectively. My research is currently supported by the Ramón y Cajal Program and the research project CGL2011-24829.

\section{References}

Allen, G.M. 1939. A checklist of African mammals. Bull. Mus. Comp. Zool. 83: 1-763.

Beolchini, F. and M. Corti. 2004. The taxonomy of the genus Tachyoryctes: a geometric morphometric approach. Ital. J. Zool. 71: 35-43.

Bucher, J.E. 1982. Family Rhizomyidae. In: (J. Honacki, K.E. Kinmam and J.W. Koeppl, eds.) Mammal species of the world. 1st ed. Association of Systematics Collections, Lawrence, KS. pp. 477-478.

Corbet, G.B. and J.E. Hill. 1991. A world list of mammalian species. 3rd. Oxford University Press, Oxford. pp. 243.

Ellerman, J.R. 1941. The families and genera of living rodents. Vol. II. Family Muridae. British Museum (Natural History), London. pp. 690.

Flynn, L.J. 1982. Systematic revision of Siwalik Rhizomyidae (Rodentia). Geobios 15: 327-389.

Flynn, L.J. 2009. The antiquity of Rhizomys and independent acquisition of fossorial traits in subterranean muroids. Bull. Am. Mus. Nat. Hist. 331: 128-156.
Heck, J.G. 1851a. Iconographic encyclopaedia of science, literature, and art. Vol II. Botany, zoology, anthropology, and surgery. R. Garrigue, New York. pp. 959.

Heck, J.G. 1851b. Iconographic encyclopaedia of science, literature, and art. Vol I. Mathematics and astronomy, physics and meteorology, chemistry, mineralogy, geognosy and geology. R. Garrigue, New York. pp. 668.

Heuglin, T. von and L.J. Fitzinger. 1866. Systematische Übersicht der Säugethiere Nordost-Afrika's mit Einschluß der arabischen Küste, des rothen Meeres, der Somáli- und der NilquellenLänder, südwärts bis zum vierten Grade nördlicher Breite. Sitzungsber. Kaiserl. Akad. der Wiss., Abt. 1. Math. Nat. Kl. 54: 537-611.

Hinton, M.A.C. 1933. Diagnoses of new genera and species of rodents from Indian Tertiary deposits. Ann. Mag. Nat. Hist. 12: 620-622.

Hollister, N. 1919. East African mammals in the United States National Museum. Part II. Rodentia, Lagomorpha, and Tubulidentata. Bull. U.S. Nat. Mus. 99: 1-184.

IUCN. 2010. IUCN red list of threatened species. Version 2010.1. Available at www.iucnredlist.org.

López-Antoñanzas, R. and H.B. Wesselman. In press. Tachyoryctes makooka (Tachyoryctini, Spalacidae, Rodentia) and its bearing on the phylogeny of the Tachyoryctini. Palaeontology.

Misonne, X. 1971. Order Rodentia. In: (J. Meester and H.W. Setzer, eds.) The mammals of Africa: an identification manual. Smithsonian Institution Press, Washington. pp. 1-39.

Musser, G.G. and M.D. Carleton. 1993. Family Muridae. In: (D.E. Wilson and D.M. Reeder, eds.) Mammal species of the world. 2nd ed. The Johns Hopkins University Press, Baltimore. pp. 501-755.

Musser, G.G. and M.D. Carleton. 2005. Superfamily Muroidea. In: (D.E. Wilson and D.M. Reeder, eds.) Mammal species of the world. 3rd ed. The Johns Hopkins University Press, Baltimore. pp. 894-1531.

Rahm, U. 1980. Die Afrikanische Wurzelratte Tachyoryctes. A. Ziemsen, Lutherstadt Wittenberg. pp. 60.

Rüppell, E. 1836. Neue Wirbelthiere zu der Fauna von Abyssinien gehörig. Part 7. S. Schmerber, Frankfurt am Main. pp. 17-36.

Rüppell, E. 1842. Säugethiere aus der Ordnung der Nager, beobachtet im nordöstlichen Africa. Mus. Senckenb. 3: 99-116.

Sabatier, M. 1978. Un nouveau Tachyoryctes (Mammalia, Rodentia) du bassin Pliocène de Hadar (Ethiopie). Geobios 11: 95-99.

Sabatier, M. 1979. Les rongeurs des sites a hominides de Hadar et Melka-Kunturé (Ethiopie). Doctoral Thesis. Université des Sciences et Techniques du Languedoc. pp. 121.

Sabatier, M. 1982. Les rongeurs des sites pléistocènes de MelkaKunturé, Ethiopie. Abbay 11: 45-64.

Wesselman, H.B., M.T. Black and M. Asnake. 2009. Small Mammals. In: (Y. Haile-Selassie and G. WoldeGabriel, eds.) Ardipithecus kadabba: Late Miocene evidence from the Middle Awash, Ethiopia (The Middle Awash series). University of California Press, Berkeley. pp. 105-133.

Yalden, D.W. 1985. Tachyoryctes macrocephalus. Mamm. Species 237: 1-3.

Received February 2, 2012; accepted March 15, 2012; previously published online May 13, 2012 